\title{
FULLY PROFESSIONALIZED TEACHER EDUCATION: AN AUSTRALIAN STUDY IN PERSISTENCE
}

\section{Terence Lovat \& Julie Hinde-McLeod}

\section{Introduction}

The many efforts towards professionalism for Australian teacher education might be described as a 'study in persistence'. Throughout the twentieth-century, teacher education slowly but inexorably developed from a regime of apprenticeship to one of full professionalism. The movement was from short 'on the job' training to full degree programs with a status akin to the training modes of other professions of significance, complete with a distinctive graduate profile and training criteria agreed by the profession and its stakeholders (cf. ACDE, 1998). . History and cultural analysis would suggest the latter regime was where teaching always belonged, but events of the nineteenth-century challenged a societal role that, hitherto, had been relatively small and selective in taking up a new charter as a large and comprehensive social agency. Be it in ancient tribal cultures, or in ancient Greece, Rome, or China, the role of the teacher was central and of high status, invariably just below the ruler and normally associated with religious knowledge and power that often brought with it a moral force beyond that possessed even by the ruler (cf. Lovat, 2003). It was a highly selective role, preserved for a special few.

While normalized and somewhat secularized in Western civilization through events like the Renaissance and Enlightenment, the role of the teacher nonetheless survived as one of high status and relative selectivity all the way down to the nineteenth-century. Some of the earliest educational moments in Australia testify in one way or another to maintenance of the kind of essential role that would justify a fully professionalized teacher education (cf. NSW, 1912; Wicks, 2005) At the same time, it was events of the nineteenth century that placed untoward pressure on that essential traditional role. It is the ramifications of this pressure that still challenge us today and may well explain why the quarter-century from 1980 onwards was characterized by an almost endless round of teacher education reviews. At the time of writing, teacher educators await the most recent and potentially most potent of these in the form of an all-party Australian Government House of Representatives Inquiry with a particularly comprehensive set of terms of reference. 
Some of the earliest incursions into mass

education in Australia were those of the churches, especially the Catholic Church. As an instance, the role of the teacher was, for Mary MacKillop (Modystack, 2000; Wicks, 2005), central to the development of the fair, just, and godly society that she envisioned for Australia. Her mission was especially around the poor and disadvantaged who, she believed, could be transformed through the caring and professional learning engendered by the dedicated teacher. To be such a teacher was a specialized art that required good training in the practicalities of content and pedagogy but also required selflessness and caring commitment that, she believed, should be the prime object of any effective training. Granted her context of belief, these latter characteristics were also features of the authentically religious. Hence, for MacKillop, the essential role of the teacher was precisely as the ancients would have had it (cf. Plato, 1945). It was selective and of high status, and implied an infusion of religious knowledge to maximize its effect. Importantly, however, it was not something one could just do, even with such infusion. To be a good teacher required a serious training regime and MacKillop was one of the first educators in Australia to insist on this for her own followers.

In public education, as it first developed in Australia, it was not so different. Many of the earliest architects of public education came from a more elite background than MacKillop, but nonetheless shared many of her sentiments and were no doubt influenced by the obvious impact that a MacKillop-type mass education had had on the most disadvantaged among Australia’s population. The impact of Catholic education on nineteenth-century Australia was proportionally far more powerful than in Great Britain from whence so many of the country's early public educators had come. Many of the products of Catholic education were, by the later parts of the nineteenth-century, wielding their own influence in Australia, especially through the trade union movement and politically through the formation of the Australian Labor Party (cf. O’Farrell, 1985).

In short, there were forces at work that would ensure a certain direction for Australian public education that would be significantly different from equivalent trends elsewhere. Hence, we find a common sentiment among the early Education Acts enacted in the colony states throughout the 1870s and 1880s. The NSW Public Instruction Act of 1880 (NSW, 1912) was an example of a document that, in many respects, MacKillop could have written. This is the case especially of those sections that specify the comprehensive role of the teacher to inspire and uplift, not only by means of establishing in children the foundations of literacy and numeracy, but by instilling moral character and a knowledge of their broader culture, much of it religious in those days. As in MacKillop's mind, so here we find the essential role of the teacher clearly presented as being of 
high status. It is a sophisticated role, designed to make a difference of the kind largely conceived by ancient societies down to this time. Logic, and the document, suggests that such a role could be effectively underpinned only by rigorous training of the most specialized and comprehensive kind.

It was the shock of the full effects of mass education that disrupted some of the flow of understandings about the teachers' role that were evident in the nineteenth century. Together with their equivalent trends internationally, the Education Acts of the 1870s and 1880s were establishing for education, and hence for teachers, a role that had been the subject of occasional rhetoric but never implemented in such wholesale fashion before. The role was that of being a social agency of change and a maker of difference for all citizens. No longer was education to be merely for the privileged, nor merely for the disadvantaged. It was to play a formal role in the formation of everyone, ideally from infancy to adulthood. In practical terms, it was a revolutionary concept, in terms of both its impact on physical resources and the sheer volume of human resources that would eventually be needed to fulfil the vision. From hereon, the challenge would be to maintain the traditional status and mystique of the teacher role, as well as an adequate training while, at the same time, mass-producing its products. It is this challenge that remains and impacts politically and in resources terms today.

\section{Mass Education and Teacher Education}

Unlike those professions with which it is often compared, the teaching profession requires in one year the numbers that some of its comparative professions need in ten. As an example, in recent years, The University of Newcastle has entered approximately 80 medical education students per year, 200 engineering students and 400 nurse education students. At the same time, it has entered well in excess of 1,000 teacher education students. Hence, while it is useful to compare some of the elements of teaching's training regime with the training regimes of professions of traditionally higher status, nonetheless comparisons and contrasts should be tempered with knowledge of the vast differences in the volume demands placed on one against the other, of the modes of interaction and the essential relationships within each, and of the resources that our society puts behind one vis $a$ vis the other.

Before overly facile comparisons of program rigour and graduate readiness are made, one should remember that, via the funding formula of the past fifteen years, Australian society has effectively suggested that teacher education can be done on the cheap, with portions of funding that pale to insignificance compared with those that support those professions with which its training is often 
compared (cf. DEST, 2005). The formula would have it that it costs about the same to put a teacher education student through an average education subject at university as it does to put a sociology student through a sociology subject and, furthermore, that it is cheaper to train a teacher than to train someone in drama. For anyone who has had the briefest purview of the professional experience costs of teacher education, the lack of empirical basis behind the formula becomes obvious. Putting the sheer volume of teacher education places required for adequate supply up against the severe resources shortfall rendered by the persistence of government to stay with an unscientific and unfounded funding formula, one begins to gain some sense of the enormity of the challenge implicit in maintaining the traditional high status of the teaching role while, at the same time, mass-producing teachers.

Yet the task of the teacher educator is to do precisely this thing. Part of the kudos or myth of the medical, legal, or engineering professions is underpinned by community perceptions that professional training in these domains works to provide the requisite knowledge and skills. In other words, the community believes that these training regimes do produce the essential professionals on whom society can rely for their knowledge and skills. Auchmuty (1980) proposed, at the birth of the modern round of reviews, that community confidence of this sort did not extend to teacher education and that, in turn, this impacted on community perceptions of the credibility which should be attached to teachers and their knowledge base. In short, the suggestion was that perceptions of inadequacy in the training regime produced a negative effect generally about the profession. This theme of the profession/professional-training nexus was taken up explicitly in the Federal Senate Inquiry into the status of the teaching profession, A Class Act (Senate, 1998), where we read that the presence of teachers with less than what might be deemed to be full university training was among those factors that “... lower the status of teachers.” (p. 180).

In this light, the Australian Council of Deans of Education (ACDE) report, Preparing a Profession (ACDE, 1998), provided, for its time, a particularly illuminating appraisal of what it is that lies at the heart of the mystique of teaching and therefore of teacher education. In 1.5.3, we read (italicized emphases ours):

Graduates should have the deep understanding of content and pedagogy which enable them to transform ... content in ways which are powerfully responsive to the particular characteristics of learners, curricula and teaching environments. 
In utilizing the language italicized above, the ACDE was drawing in part on research that was coming to form much of the basis of quality teaching and quality teacher education. It would be the research around what is broadly termed 'Quality Teaching' that issues of intellectual depth and transformation of learners would be teased out and demonstrated in such powerful fashion. In the USA, the Carnegie Corporation’s 1994 Task Force on Learning (Carnegie, 1994) challenged earlier conceptions of a limited role for teaching with bold and assertive evidence-based statements about the power of teachers to effect change in student achievement provided they went about their task in particular ways.

The Carnegie Report was explicit in making the link between achievement and the teacher’s power to make a difference. The report specified the criteria of achievement that had shown up in its underpinning research and so, in turn, identified the range of learning skills that should constitute the targets for teacher and school learning objectives. While not underselling in any way the centrality of intellectual development as the prime focus and objective of teaching and schooling, the report nonetheless expanded significantly on the more predictable, tried and true features of intellectual development to speak explicitly of the broader learning associated with skills of communication, empathy, reflection, and self-management. Together with notions of analysis, synthesis, and relational capacity, this is the language of those forms of 'deep understanding' that 'transform' content in ways that impel 'powerfully responsive' learning relations.

Hence the notion of 'intellectual depth', so central to modern regimes of quality teaching, was from the beginning defined in broad fashion to connote not only depth of factual learning but, moreover, induction into the profound learning to be derived from competencies such as interpretation, communication, negotiation, and reflection, with a focus on self-management. In a word, the teacher's job was conceived of as being quite beyond the kinds of achievement most easily measured by standardized testing to being one which engaged the students' more sophisticated skills levels concerned with development of such features as 'communicative capacity' and 'selfreflection'. Elsewhere, the important connections between such a view of teaching and the role of the teacher as an agent of values inculcation is spelled out (cf. Lovat, 2005). Evidence-based research of the later 1990s (cf. Darling-Hammond, 1997) into the impact of quality teaching merely served to confirm the thesis that the full effects of such comprehensive learning could only come as the result of sophisticated, well-informed and highly skilled teaching.

\section{Evidence-based Research and Professionalized Teacher Education}


6

In short, evidence-based research has shown that teaching is a highly developed art and science, revolving around the kinds of complex knowledge and skills that could normally only be expected to result from a formidable training regime. Later research has provided further evidence that effective teacher education is a vital component in eliciting those comprehensive and profound forms of student achievement suggested by Carnegie (cf. Darling-Hammond, 2000; Carnegie, 2002). In all this work, the formidable training regime presents as the same species of unqualified higher education that, one way or another, forty years of reviews and inquiries into teacher education in Australia have reaffirmed as essential if teaching is to do its job for the nation. Martin (1965) first threw down the gauntlet to a nation that had slipped into a pattern of mass-producing teachers in ways that were destined to fall short of both traditional aspirations of high status professionalism and of newfound expectations of teacher impact. Martin saw the task of teaching as far too important to have anything but the best resources of the nation's higher education available to it.

As it transpired, resistance and elitism in the nation's universities of the day meant that Martin's vision was not realized. In the immediate aftermath of Martin, a binary system of higher education was established and, for the most part, it was the less well-resourced and non-research-based end of the system that became the main venue for teacher education. Hence, a decade and a half on from the Martin Report, we see the relevance of Auchmuty (1980) in pointing to some of the weaknesses of a training regime that, according to this report, was showing signs of being overly targeted to producing functional skills for 'Day One' readiness rather than the sustained knowledge and skills required for full professionalism and long-term impact. While Auchmuty’s main concern was around the issue of discipline knowledge, in many ways, Correy (1980) made the same point in relation to pedagogical craft. Both reports, coming just fifteen years on from Martin, revealed something of the loss for teacher education that had been rendered by the Government's lack of will to implement this latter report.

As suggested above, in the quarter of a century or so since Auchmuty and Correy, there has been a spate of reviews, inquiries and reports, most urging in their own ways the same attention to full professionalism for teacher education and its various dimensions. Evidence would suggest that, in spite of the difficulties identified above related to volume demand and under-resourcing, teacher education has heeded the advice provided by these reports and arrived as a fully professionalized regime alongside the regimes of its peer professions. In stark contrast to the recent past when the stereotype of teacher education was one of 'easy to get into' and 'second best' in terms of choice, in 
the past few years, teacher education has become one of the most competitive regimes in Australian higher education.

In terms of 'easy to get into', one might again cite The University of Newcastle as fairly typical of those universities where teacher education can be directly compared with professional training regimes like those of medicine, engineering and accountancy. Entry scores of the past few years reveal that any teacher education student could have entered accountancy, most could have entered engineering and a surprising number have scores that would have allowed an interview into medicine. Indeed, there are numerous records of students who entered medicine or law under the societal pressure that comes with gaining high entry scores, but who quickly moved to their area of real preference, namely teacher education. In terms of 'second best', for the last few years, places in most teacher education programs have filled easily without having to move beyond first preferences. Indeed, highly competitive entry scores sitting behind first preferences have often proved to be insufficient to secure a place in teacher education.

The effects noted above, which are fairly typical of what has transpired nationally in the twenty-first century, have not been accidental. They have come through a combination of external forces. One of these relates to a burgeoning knowledge economy which casts teacher education as a natural preparation for life and career skills beyond those related merely to teaching in schools (cf. ACDE, 2001). Another relates to important work done within the profession, where employer systems, unions and teacher educators have worked together to build the image of the profession as one where teachers can make a difference, and providing the kinds of training regimes that match this image.

Status is clearly important in impelling some of these effects, and 18.1\% of a sample of 813 teacher education students who responded to a 2004 survey at The University of Newcastle agreed that the attraction to teaching related to professional status. However, the same survey revealed that it is the image of teaching that is more instrumental as an attraction with $73.7 \%$ of students saying they were attracted to teaching because they wanted to 'make a difference', $47.7 \%$ because they wanted to act as a role model and $49.7 \%$ because they saw teaching as a chance to influence others. If this is a reliable indicator of the current mindset of teacher education students, it seems that those age-old teaching foundations of commitment and compassion, espoused by MacKillop in the earliest days of Australian education, are alive and well. 
In the context of all the above, one of the challenges of the current era is seen in the likes of the 2005 Victorian Government Report on teacher training (VIC, 2005) that speaks of the overarching priority of 'teacher readiness' in ways that defy the reality of other professional training regimes. Unless qualified, this has potential to take us back to the 'Day One', short-term readiness that Martin, Auchmuty and Correy, in their different ways, all saw as the main problem with teacher education as it was functioning in their time. On the surface, the Victorian Report seems to infer that 'teacher ready' means a teacher being fully competent to step into the identical role of classroom teacher as the teacher next door, almost without regard to their different depths of experience. If not qualified in some way, this is the equivalent of suggesting that medical education should produce a doctor who can perform surgery on the first day of internship, a first-day lawyer should be able to step straight into the role of prosecution or defence counsel, or a new engineering graduate should be sufficiently ready to take on a major building project unaided. It is only when such comparisons are made that the full force of unreflective analysis in this notion becomes evident.

The reason that many teachers and teacher educators react to the notion of 'teacher ready' put by the Victorian Report is that it tends to reflect those unrealistic expectations that have dogged beginning teachers over time and propelled a disproportionate number of them out of the profession within a few short years of beginning. In spite of this, the notion does maintain a cosmetic plausibility owing to a persistent community sentiment that suggests that there are radically different specialization foundations between teaching and its peer professions. Unlike medicine, law and engineering, there is a naïve and dangerously uninformed community view that teaching is a practice that anyone can do, and so the role of teacher education should simply be to hone up and fine-tune those basic skills required for first-day competence and survival. If this is the view that dominates the findings of the current Australian Government House of Representatives Inquiry (HoR, 2005-2006), then the likelihood is that all of the good effects noted above, and the injunctions of the annual round of reviews that stand behind those effects, will be undone and teacher education will spiral downwards to repeat the very effects that the reviews were set up to counter.

\section{Notions of Apprenticeship and School-Based Teacher Education}

Granted the unreflective analysis and uninformed community sentiment specified above, the plausibility of apprenticeship as a teacher training device presents as highly credible. As a specific 
form of apprenticeship, the notion of 'school- based teacher education' is currently being promoted as a "targeted approach that is market-based ...for subject and locality based teacher shortages” (Buckingham, 2005:11) As this model is conceived, trainee teachers are predominantly based at a school 'site' and learn 'on the job', often with the enticement of ongoing employment upon completion of their training. A recent Australian Government sponsored report (Ingvarson, 2005) appears to endorse a version of school-based teacher education in the form of the Bachelor of Learning Management (BLM) at Central Queensland University. The de facto endorsement comes through the report's findings that suggest a greater level of satisfaction from a range of stakeholders, including the candidates themselves, with the BLM than with more traditional programs. On the surface of it, such findings seem to present a challenge to those who hold to the view that the long-term status and effectiveness of the teaching profession requires a form of training akin to that of its peer professions. It is beyond the scope of this article to offer a full appraisal of the intentions and methodologies of the study on which the Government report is based but it is within its scope to suggest that the study was sufficiently limited to compel the report's findings being treated as informative rather than definitive. It is also within its scope to uncover any weaknesses in its underpinning assumptions. Prime among these weaknesses is the fundamental notion of apprenticeship as providing a suitable model for teacher education.

Traditionally, ‘apprenticeship’ connotes an indenturing of a novice to the service of a master for instruction in a trade. The inherent assumption behind apprenticeship is that the transmission of the skills of the trade from the master to the novice is sufficient for competence to be attained. It is an ideal model for a trade like carpentry, for instance, where the characteristics of each item of timber are easily categorized, the potential products of timberwork easily identified, and the various methods of dissection and reassembly of the timber in order to make the products are easily conveyed and modelled. It might be said that common artefacts of carpentry are consistency and predictability. On the other hand, teachers deal with learners whose most common characteristic is difference, be it in terms of age, ethnicity, socio-economic background, beliefs and values, as well as in terms of academic, physical, emotional, social and spiritual development. Moreover, these differences are to be found worldwide in very different contexts of learning. Indenturing a trainee teacher to one 'master' in one context may produce a range of skills pertinent to the particular class in question relative to the strengths and weaknesses of the master teacher but, on its own, it would do little to prepare the teacher for the complex array of differences that characterize the various contexts of learning and the many and varied dimensions of learning to be found within them. 
10

University-based teacher education makes use of the best features of apprenticeship in the forms of practicum and internship but it normally ensures that a student experiences a range of learning contexts and of master teachers. More importantly, it builds the foundations of broad teacher competence and flexibility through foundation studies in psychosocial development and educational theory that expose the future teacher to the evidence elicited from close to a century of educational research and to many centuries of educational thought. Furthermore, it provides the depth of understanding of discipline knowledge and the educational ramifications of that knowledge which Shulman (1987) described as 'pedagogical content knowledge’.

Through all this, instead of the very limited set of experiences in one or two contexts that characterizes apprenticeship, university-based teacher education offers to students the foundations of that depth of understanding, lateral thought, and flexibility that allow for mobility and effective service of the myriad students in their vastly different contexts that characterizes modern education. Similarly, the apprenticeship model fails to provide for students neither an opportunity to 'stand back'and reflect on the actions in which they are expected to engage, nor to compare these actions with those of other beginning teachers in different teaching contexts dealing with different learners in different educational systems. As the Australian Council of Deans of Education (ACDE, 2005) has argued, a culture of lifelong learning requires knowledge about learning contexts and learner identities which are impossible to develop through a one-site specific apprenticeship:

Today’s teachers must deal with rapidly changing discipline and pedagogical knowledge; with increasing student diversity; and with new information and communications technologies. These changes demand unprecedented professionalism and a complex range of knowledge and skills” (P. 3)

These are not the kinds of knowledge and skills that can be transmitted to a developing teacher by one person at one site through an apprenticeship. They are the knowledge and skills constructed through interaction with multiple teaching contexts, multiple learners, and with multiple opportunities for reflection 'for, in and on' teaching actions (McLeod and Reynolds, 2003; Grushka, McLeod and Reynolds, 2005).

In short, we would argue that the apprenticeship syndrome for teacher education represents a reactive commodification of teacher training that comprises a short-sighted response to a situation that has arisen because of governments' abdication of investment in education despite consistent national and international studies that stress the economic benefits of education to individuals and nations (ACDE, 2005). The long-term implications of localised recruitment of teacher trainees to 
address local shortages are also disturbing in

terms of their potential for cultivating academic, social, and cultural insularity despite a national vision of education as a tool of social cohesion to overcome “ ... attitudes and ideas which are founded in ignorance, prejudice and fear” (ACDE, 2005:7).

\section{Balancing the Best of Apprenticeship with the Best of Higher Education}

Successful teacher education for the twenty-first century demands full professionalization through a university-based program that incorporates the contextual advantages of school-based teacher education without the reproductive disadvantages of an apprenticeship model. At The University of Newcastle, the ‘School University Partnership in Teacher Education’ (SUPTE) program provides an example of constructive interaction between teacher education students, practising teachers, school learners, and teacher educators. SUPTE has developed from a research-grounded ideology which focuses on teacher quality being developed through reflection 'for, in and on' action (McLeod and Reynolds, 2003; Grushka, McLeod and Reynolds, 2005). For teacher education students, SUPTE structures opportunities for reflection in different educational contexts and with a wide variety of participants in the educational process. In order to maximize this potential for supported reflection, SUPTE constructs a series of professional interactions in different educational sites. This series of professional interactions consists of the following:

\section{- $\quad$ Teacher education students with teachers and learners in classrooms}

Beyond the standard practica required for employability, The University of Newcastle's teacher education students spend extended periods of time in a range of schools undertaking different roles. In the first year of their program, they link with one teacher and one class to observe teaching actions and learning responses, to discuss these observations on-site with the teacher and then to reflect on their own learning when they return to the University. In the second year of their program, teacher education students have the opportunity to follow the development of children's learning in one class throughout the year. They do this through: observing how the class teacher manages learning and teaching for different learners and different curriculum areas; discussing these with the teacher, with teacher educators and with peers; and, practising a variety of teaching strategies in order to support learning in ways suitable to the class in question. In the third year of their program, teacher education students are encouraged to move beyond their local pedagogical 'comfort zone' in order to confront the challenges of different contexts. In supporting them, the University has developed a strong network of sites throughout the state, particularly in rural and remote areas. For many students, the experience of teaching at a school totally different from 
anything they have previously known can be life changing. At the very least, it prepares them for the variety of contexts in which a teaching career might be lived out. Many seek employment in these previously unfamiliar areas based on this experience and, the evidence would suggest, these same teachers are valued highly by their new communities (McLeod, 2000). In the final year of their program, teacher education students interact with one school, getting to know the students, staff and community and then undertaking a ten-week internship where they take on the role and responsibilities of the teacher.

- $\quad$ Teachers with teacher education students and teacher educators at university

Teachers are seconded from local schools to work with teacher education students in their university studies. These teachers work with teacher educators to design courses in curriculum content, education, and pedagogy. They teach beside teacher educators in lectures and workshops, and co-design in-school experiences. The benefits to all parties arise from the currency of informed theory and practice. In addition to teaching responsibilities at the University, teachers from schools are involved in governance as members of committees and advisory bodies.

- $\quad$ Teacher educators with teachers and the community in schools

Teacher educators work with teachers in schools to support professional development and collaborative teacher research as well as staff selection. They also participate in decision-making with school communities in management and direction.

- Teacher education students with academics and students from other disciplines

All teacher education students in 4-year programs at The University of Newcastle undertake a double degree, comprising a Bachelor of Teaching together with a Bachelors degree in their discipline area. This interaction has proven to be extremely valuable in its contribution not only to the breadth and depth of students' knowledge of discipline content, but in the opportunities it presents for their reflection on different teaching practices. For example, primary teacher education students, through their studies in the discipline of Social Work, develop an understanding of the issues of home-school interactions beyond the classroom as well as the skills to work with family, agencies and other professionals concerned with a child's education. As graduates, their work embraces not only the children who are their students, the principal and teaching colleagues who are their professional peers, but parents also who are now both ‘customers' and 'co-educators' with whom they must “ ... develop close partnerships between home and school.” (ACDE, 1998:17). 
We would argue that the graduates of a program like the one described are 'teacher ready', though in a way significantly more profound than that described in the Victorian Report (VIC, 2005). In contrast to the notion that readiness implies Day One skills preparation, these graduates have been assessed as having the depth and breadth of knowledge and skills of a fully professionalized teacher education program and the advantages of contextual understanding and flexibility. Indicators of this have been in the comparatively high employability rates into both public and private systems over many years and, moreover, by the extent to which they have been the subjects of targetted recruitment by international agencies to teach overseas.

\section{Conclusion}

The paper has argued that professionalism of teacher education is one of the pillars of professionalism in teaching generally. The perspective taken is that this is not a new concept, teaching as a high status profession being as old as the records of civilization itself, and the notion of high status training being a necessary artefact implicit in these records. It has argued furthermore that these are the perspectives we find in the earliest instances of formal education in colonial Australia, be they of public or private education. While these perspectives were tested in the fires of the mass growth of education throughout the twentieth century, the various reviews of and reports on teacher education since 1965, and especially since 1980, have focussed, in one way or another, on the need for high quality and fully professionalized teacher education as a necessary attachment to teaching as a quality and high status profession, and that this form of teacher education is best provided in a higher education context. The article has identified what the authors perceive as a contemporary threat to this development of thought, seen recently in the form of 'quick fix' solutions to problems of supply and problems rendered by governments' inadequate resourcing of teacher education for the last few decades.

The article urges the current Australian Government House of Representatives Inquiry, in particular, to take note of the long history of teaching and teacher education, of its traditional high status and of the overwhelming importance of maintaining this tradition at the same time as encouraging teaching to adapt to its new global challenges. It has offered an instance of a program found typically in Australian universities which integrates the best of the higher education perspective with the need for effective practical experience and it has pointed to some of the local and international evidence of this program's capacity to prepare quality teachers for a quality profession. This program is just one of many instances that comprise an Australian study in persistence, on many occasions against the odds, of preserving and maintaining professionalism in 
teacher education and ultimately in teaching itself.

\section{References}

ACDE (1998). Preparing a profession: Report of the national standards and guidelines for initial teacher education project. Canberra: Australian Council of Deans of Education.

ACDE (2001). New learning: A charter for Australian education. Canberra: Australian Council of Deans of Education.

ACDE (2005). New teaching, new learning: A vision for Australian education. Canberra: Australian Council of Deans of Education.

Auchmuty, J. (1980). Report of the national inquiry into teacher education. Canberra: AGPS.

Buckingham, J. (2005). Good teachers where they are needed, Issue Analysis, 64: 1-19.

Carnegie Corporation (1994). Every child can learn. Available at:

http://www.carnegie.org/sub/pubs/execsum.html (accessed 12/2/06).

Carnegie Corporation (2002), Teachers for a New Era. Available at:

http://www.carnegie.org/cgi-bin/printpage/printit.pl (accessed 12/2/06).

Correy, P. (1980). Teachers for tomorrow: Continuity, challenge and change in teacher education in New South Wales: Report of the committee to examine teacher education in New South Wales. Sydney: Government Printer.

Darling-Hammond, L. (1997) The right to learn: A blueprint for creating schools that work. San Francisco: Jossey-Bass.

Darling-Hammond, L. (2000). How teacher education matters. Journal of Teacher Education, 51: 166-173.

DEST (2005). Our universities: Backing Australia's future. Available at: 
Grushka, K., McLeod, J. and Reynolds, R. (2005). Reflective practice in teacher education: Theory and practice in one Australian university. Reflective Practice, 6: 239-249.

HoR (2005-2006). Inquiry into teacher education. Canberra: House of Representatives Parliamentary Committee for the Inquiry into Teacher Education.

Ingvarson, L. (2005). Evaluation of the Bachelor of Learning Management (BLM) at Central Queensland University (CQU). Available at: http://www.acer.edu.au/research/programs/EvaluationofBLMatCQU.html (accessed 6/2/06).

Lovat, t. (2003). The role of the teacher: Coming of age. Canberra: Australian Council of Deans of Education (Occasional Papers).

Lovat, T. (2005). The national framework for values education: Implications for research on quality teaching. New Horizons in Education, 112: 36-46. From the keynote address at the inaugural National Values Education Forum, Canberra, May, 2005. http://www.wef.org.au/files/speeches_lovat2004.pdf

McLeod, J. (2000) Beginning to Teach: Explorations of Context through Lived Experience Unpublished PhD, The University of Newcastle, Australia.

McLeod, J. and Reynolds, R. (2003). Planning for learning. Melbourne: Thomson Learning.

MACQTECT (1994). Desirable attributes of beginning teachers. Sydney: NSW Department of School Education.

Martin, L. (1965). The report of the committee on the future of tertiary education in Australia. Vols. 1-3. Canberra: Australian Government Printing Service.

Modystack, W. (2000). Blessed Mary MacKillop: A woman before her time. Sydney: Lansdowne.

NSW (1912). Public instruction act of 1880 and regulations. Sydney: William Applegate Gullick. 
O’Farrell, P. (1985). The Catholic Church and community in Australia. Melbourne: Thomas Nelson.

Plato (1945). The Republic of Plato. (transl. F. Cornford) New York: Oxford University Press.

Senate (1998). A class act: Inquiry into the status of the teaching profession. Canberra: Senate Employment, Education and Training Reference Committee.

Shulman, L. (1987). Knowledge and teaching: Foundations of the new reform. Harvard Educational Review, 57: 1-22.

VIC (2005). Inquiry into the suitability of pre-service teacher training in Victoria. Melbourne: Education and Training Committee, Parliament of Victoria.

P. Wicks (ed.) (2005). Mary MacKillop: Inspiration for today. Sydney: Trustees of the Sisters of St Joseph.

Professor Terence Lovat is Pro Vice-Chancellor (Education and Arts) and Dr Julie HindeMcLeod is Senior Lecturer and Coordinator of Primary Teacher Education at The University of Newcastle, Australia 